\title{
Combined sewer overflow in Shenzhen, China: the case study of Dasha River
}

\author{
G. Talamini ${ }^{1}$, D. Shao ${ }^{2}$, X. $\mathrm{Su}^{2}$, X. Guo ${ }^{1} \&$ X. Ji ${ }^{1}$ \\ ${ }^{1}$ Shenzhen Graduate School, Harbin Institute of Technology, PRC \\ ${ }^{2}$ Hong Kong City University, PRC
}

\begin{abstract}
The enormous process of urbanization, which is changing the Pearl River Delta (PRD) into the largest urbanized area of the world, is causing severe pressure on the water systems of the entire region. Urban river networks in dense urban environments, like in Shenzhen administrative territory, underwent a radical reduction in terms of size and complexity. Contextually, the impact of urbanization can be measured on significant coverage by impervious surfaces and related increase of surface runoff. Additionally, unsorted wastewater infrastructures are contributing to create the conditions, which can determine the contamination of water bodies during intense rainstorm events. Urban streams in Shenzhen are currently under transformation. Notwithstanding the considerable resources invested by the city administration in constructing new sewage infrastructures, during intense rainstorm events, various combined sewers are overflowing into the riverbeds, significantly worsening water quality. This paper uses the Dasha River in Shenzhen to systematically determine the causes of overflow and the possible strategies of intervention. The analytical study of wastewater drainage design of the Dasha River is here combined with on site surveys. To address the issue, different strategies of intervention are possible. On a medium time horizon, separating stormwater discharge from sanitary sewage is the most sustainable scheme. On a long term perspective, implementing the Sponge City precepts can significantly contribute to prevent combined sewer overflow (CSO).
\end{abstract}

Keywords: combined sewer overflow (CSO), impervious surface, Shenzhen, Dasha River, Sponge City. 


\section{Introduction}

An extraordinary urbanization process that occurred in the last four decades has been turning the PRD into the largest urbanized area of the world. As stated by the World Bank [1] if considered as a single urban area, the PRD is the largest in the world both in terms of land coverage and population. The effects of this fast growing urbanization are so vast, that are observed using remote sensing $[2,3]$.

The substitution of natural soil with impervious surfaces is impacting on hydrological cycle, water table, surface heating balance, soil erosion, and biodiversity [4-8]. Understanding impervious surface distribution and dynamics is relevant to the current topic: impervious surfaces are preventing rainwater infiltration, and increasing surface runoff to rivers or artificial canals and sewers. As demonstrated by Liu et al. [9] in Shenzhen, one of the fastest growing urban areas of PRD, there is a significant correlation between water quality indicators and impervious surface area. What is here under analysis is the particular condition in which surface runoff causes CSO. Using Dasha River in Shenzhen as a case study, the aim of this paper is to demonstrate how surface runoff during intense rainstorm events and CSO into stream beds can be correlated. Furthermore, this work is investigating the strategies to address the issue.

\section{Approach}

For this paper, we postulate that impervious surfaces produced within urbanization are the main cause of surface runoff in urban areas of PRD. On this issue, previous researches has shown a significant correlation between the increase of impervious surface and increase in the volume of stormwater runoff [10-12]. We postulate that hydrological conditions of urban streams can be altered, not only by the relevant contribution, in terms of magnitude and quality, given by surface runoff, but also by CSO, as it is already amply demonstrated [13-15].

Given the limited capacity of wastewater treatment, we hypothesize that rainstorm runoff is the greatest stressor at the scale of the sewer tributary system.

The analysis is defined around three main questions:

1) How does the Dasha River sewer system function?

2) What are the necessary conditions for CSO?

3) Which are the most sustainable strategies to address the issue?

\section{Case study: Dasha River renovation project}

\subsection{Background}

The Dasha River is located in Nanshan district. It originates in Yangtai mountain, beginning from Chang Piling dam, crossing the whole Nanshan district and flowing into the Shenzhen Bay. Dasha River is an important ecological axis connecting Nanshan district to one of the core central area of Shenzhen. It also 


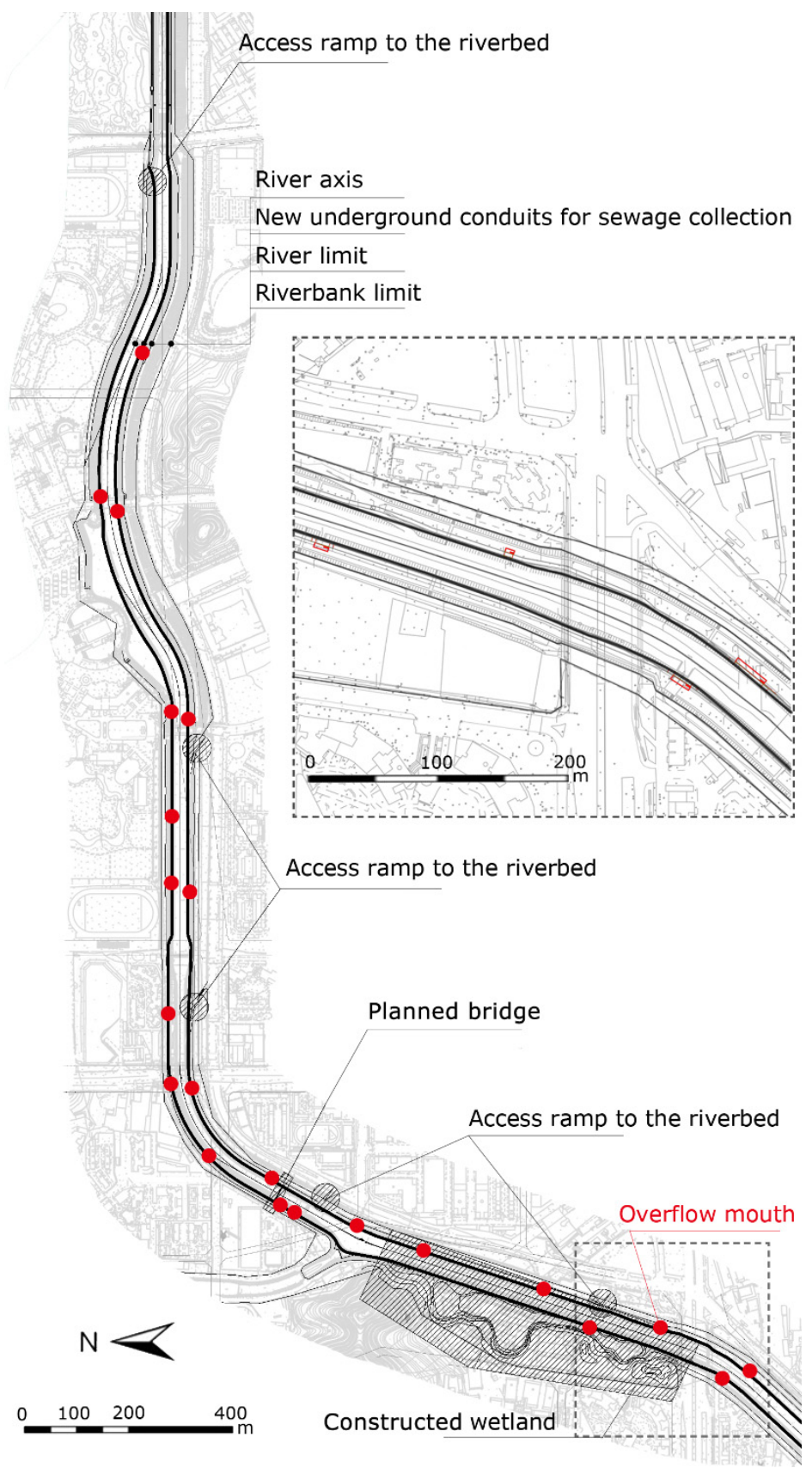

Figure 1: Portion of sewage construction project. 
represents a potential green ecological corridor linking Yantai Mountain, Tanglang Mountain and coastal recreation zones. However, Dasha River is facing severe pollution issues, affecting the surrounding urban environment. For these reasons, in 2006, Shenzhen government and Shenzhen Water Group proposed the "Dasha River ecological environment construction plan". The plan aims to construct a comprehensive treatment infrastructure, in order to meet the standards of modern coastal cities, connecting the ocean to mountainous regions and green urban areas. The plan combines comprehensive measures of flood control, pollution control and landscape regeneration, with the goal of recovering the natural river ecological environment.

\subsection{Preconditions}

Following the implementation of river engineering, which started in the 1990s, Dasha River has reached flood control standard of "once per 100 years" (the river can handle the highest flood which take place once every 100 years), reaching in some areas "once per 200 years" [16]. At this stage the river was already connected to a drainage network serving the contiguous urban areas and provided with flood control system.

\subsection{Project tasks}

These were the main project tasks [16]: improving water quality, controlling floods and constructing the basic water quality conditions to transform the river into an ecological corridor.

1) Water quality improvement:

due to the complex existing situations, being difficult to meet the IV national surface water standard in a short time, the project evaluates to use the water only for decorative purposes. The project design must take this into account.

2) Flood control standards:

main stream "once per 200" to "once per 100 years"; tributaries "once per 50 years".

3) Revetment restoration:

after meeting flood control standards requirements - constructing or maintaining specific structures - the project can combine water quality improvement and the ecological restoration of riverbanks.

\subsection{Project features}

The regeneration project has been developed by Shenzhen Water Management and Design Institute starting from 2006, and implemented starting from 2013. The main goal of the project was the construction of a sewage infrastructure under the river banks, collecting all the culverts, which were previously discharging into the river. The new infrastructure consists of 2 underground conduits, which indistinctly collects wastewater and stormwater runoff. The conduits are linked to 


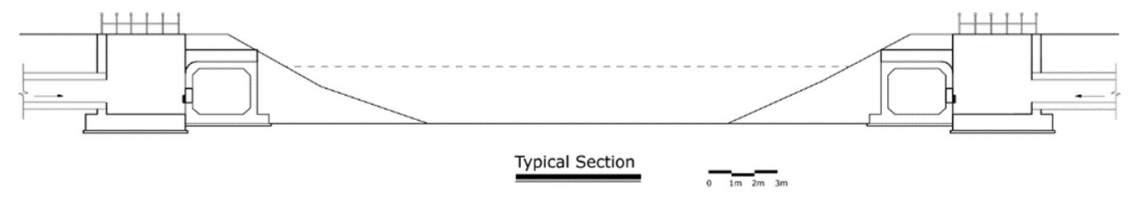

Figure 2: Dasha River cross-section.

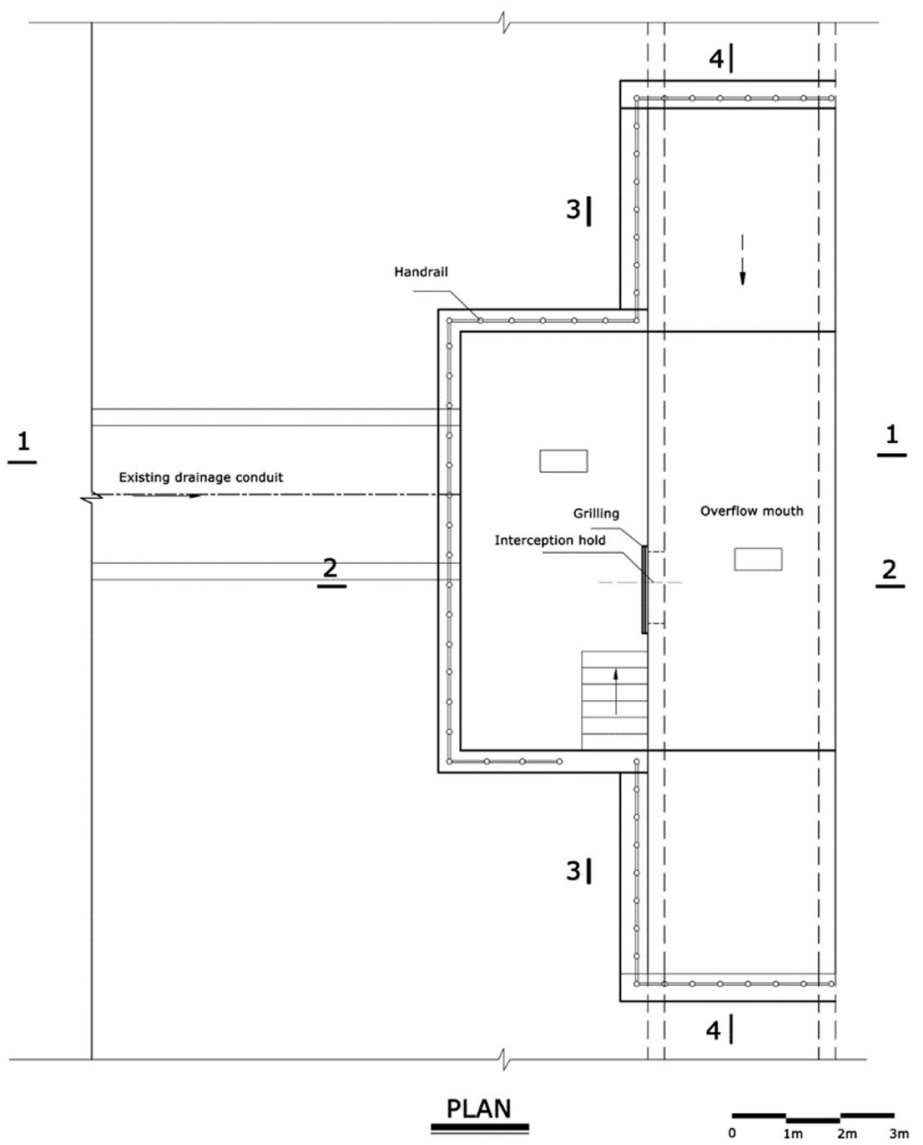

Figure 3: Overflow mouth plan. 
a terminal pumping station, which is dispatching the waste water to a treatment plant. They are made out reinforced concrete and located on the side of the river banks. The conduits have variable section, ranging from $2 \mathrm{~m}$ side squared section (upstream) to a larger rectangular section $(3 \mathrm{~m}$ by $6 \mathrm{~m})$ downstream. Their side walls are $80 \mathrm{~cm}$ thick and, according to the designers, they are meant to last for at least 50 years [17]. All along the pipes, in correspondence with the catchments, are located big superficial openings of about $4 \mathrm{~m}$ by $5 \mathrm{~m}$. These openings are designed for two different purposes: overflows management and maintenance inspections.
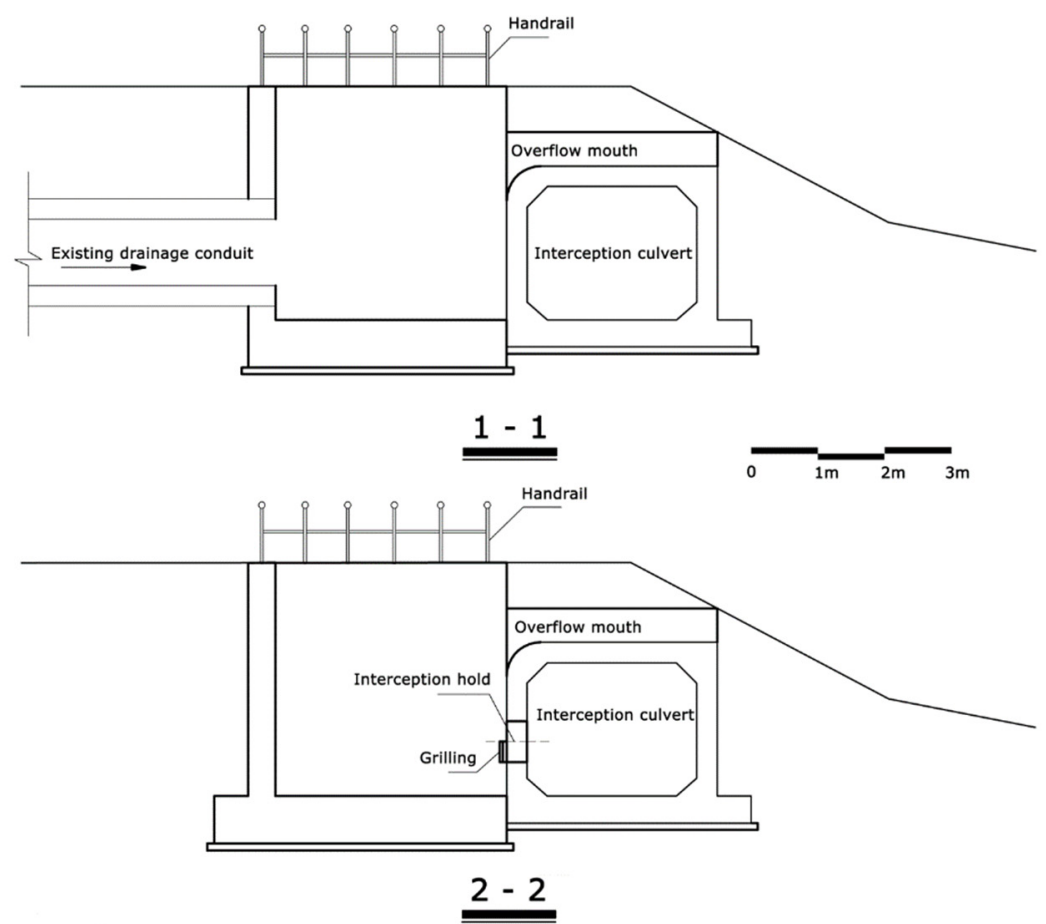

Figure 4: Overflow mouth: sections.

The system functions as follows: the water is collected from discharge pipes into an open air pool. The pool is connected to the underground collectors through a small opening (that ranges from $0.6 \mathrm{~m}^{2}$ to $0.8 \mathrm{~m}^{2}$ ) [17]. The dimension of this opening is calculated in order to control the flow. In case of an intense period of rain, after an hour, the pool will be totally filled up and the water will start to overflow into the riverbed. This period of time (one hour) is calculated considering the high pollution of stormwater runoff within this period, both for the precipitation of atmospheric pollutants and for the erosion of the ones deposited on the ground [17]. In fact, current calculations states that stormwater runoff discharges into the river 2704 tons $\mathrm{COD}_{\mathrm{Cr}}$ per year from NPS pollution, which are 
approximately equal to 10.8 million $\mathrm{m}^{3}$ of domestic sewage [16]. Considering that up to $80 \%-90 \%$ of the pollutants should be washed away by the first hour of rain, designers advance that the water that will overflow directly into the river after one hour (planned period of time) should be rather quite clean [17].

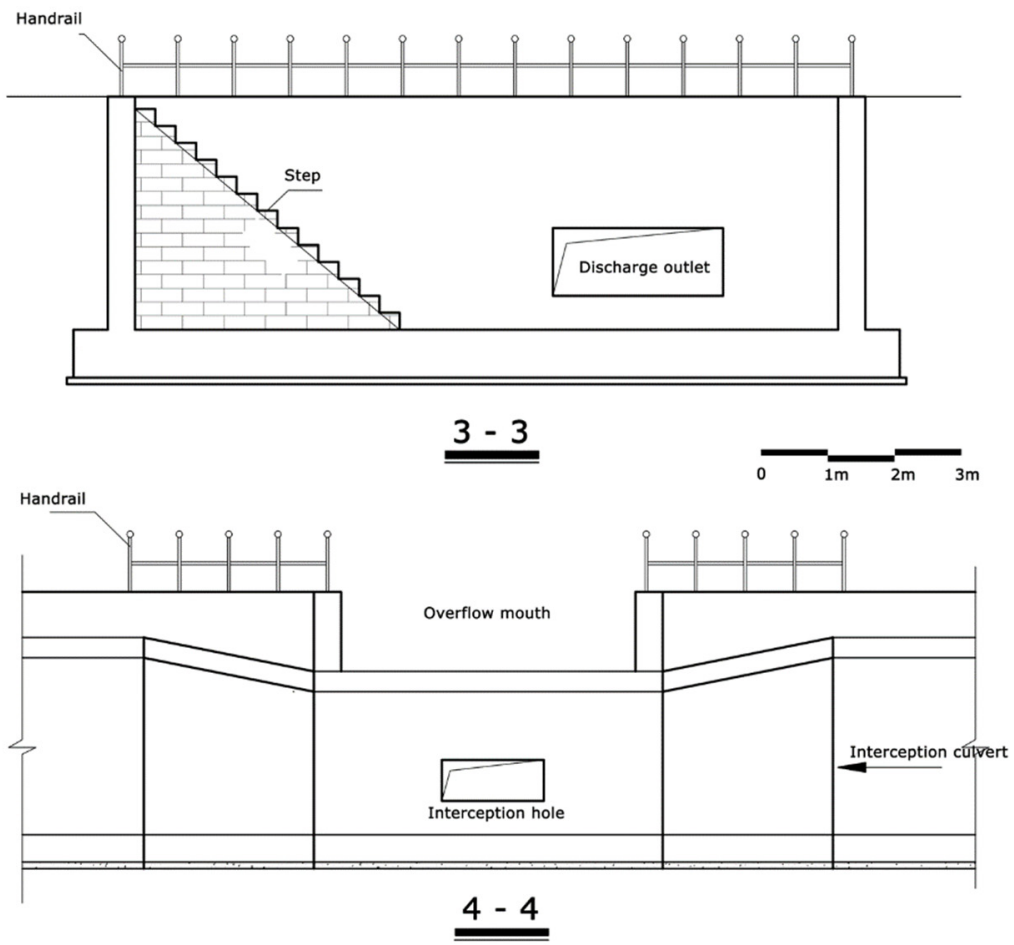

Figure 5: Overflow mouth: sections.

To build the new sewage infrastructure the former concrete banks has been destroyed and substituted with less impervious surfaces: the bank are greened, covered by turf, but still maintaining a geometric and regular section.

The project started back in 2006-2007 and costs 4,600,000,000 RMB. The construction started in October 2013 and it was supposed to be completed by the end of 2015 [17].

According to the Water Resources Bureau of Shenzhen municipality, by July 2015, Dasha River comprehensive renovation project had been completed by $95 \%$. Water quality registered a great improvement. According to the Shenzhen State Environment Report of the first quarter of 2016, the water quality of Dasha River has reached the IV national surface water standard. And excepting the areas occupied by facilities, about $100 \%$ of revetment surfaces has been covered by vegetation, counting for new $360,000 \mathrm{~m}^{2}$ of green areas [18]. 


\subsection{Critical aspects}

The project present several critical aspects, which are due to many factors, endogenous and exogenous. In regard to CSO, these issues can be divided into two main categories: preconditions and structural limits.

1) Preconditions:

The new sewage system is provided with two treatment plants located along the river area: Nanshan treatment plant and Xili treatment plant. However, due to persisting problematic of combined sewers, still a relevant quantity of sewage is released into the river during CSO. The total urban drainage area served by the new sewage infrastructure is claimed to cover $42.18 \mathrm{~km}^{2}$. The $62 \%$ of this area still presents mixed (stormwater and sewage) discharge, while only $38 \%$ of it is provided with separate systems (sanitary sewers and stormwater runoff). The total amount of sub-catchments connected to the new system are 127 , of which $87 \%$ are combined sewers [16].

2) Structural limits:

Water treatment facilities are undersized: currently, the wastewater discharge in dry season is $90000 \mathrm{~m}^{3} / \mathrm{day}$, while the maximum total capacity of the treatment plants is $100000 \mathrm{~m}^{3} /$ day. It is evident that in case of rain the system is not able to handle the extra runoff discharge.

\section{Combined sewers}

Currently, Dasha River sewage system can be technically defined as a combined sewer. Separating sanitary sewage from stormwater runoff must involve thousands of families and the implementation process can need a long time. In fact, the mixture of the two flow is happening often at the source (in buildings and proximity). Combined sewers were common at the early stage of development of urban sewerage systems, back in the late 19th and early 20th centuries, and they still represent a problem for many cities were they have been constructed. Combined sewers require much larger and more expensive treatment facilities than sanitary sewers and they are easily overflowing. In the case of Shenzhen, or any other city with similar climate, the intensity of wet precipitation can be so high, that preventing sewers from overflowing is much more difficult than in a temperate climate zone.

\section{CSO in Dasha River}

Being the majority of the sub-catchments combined severs, in case of overflow the wastewater discharged into the river is not exclusively composed of stormwater runoff, but heavily contaminated by domestic and industrial severs. Therefore, although the stormwater runoff after one hour of heavy rain could be not severely polluted, the chemical composition of the rest of the sanitary sewage is unaltered. 


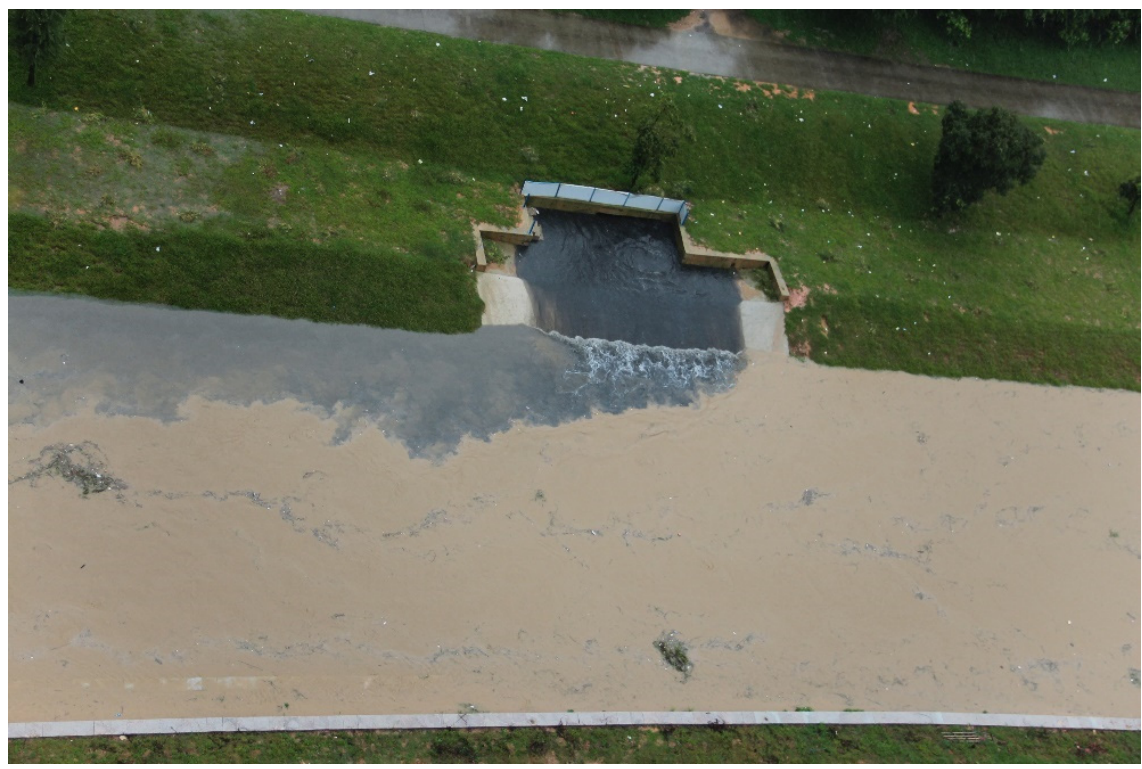

Figure 6: CSO in Dasha River: 27 July 2015.

\section{Pollution mitigation strategies}

There are mainly two different kind of strategies that can be undertaken in order to address the issue: engineered systems or green infrastructures. The second ones has been proved to be more sustainable and they are nowadays implemented in several parts of the world under different names:

Low Impact Development (LID), Sustainable Urban Drainage Systems (SUDS), Water-Sensitive Urban Design (WSUD) and Sponge City. Anyhow the implementation of these strategies can require a long time, since the system must be vastly applied in order to produce relevant effects. Additionally, in a subtropical climate it is necessary to construct a great number of ponds for water conservation. Their size have to be calculated in accordance with the precipitation patterns, which means they need to be able to collect a wet precipitation of $100 \mathrm{~mm}$ or more of rain per day.

It has been demonstrated that permeable pavements could have a significant impact in reducing stormwater runoff [19-21]. However, substituting the pavements of an already developed area can be really demanding in economical terms.

Solving the problem without reducing stormwater runoff could be done treating the CSO with green infrastructures. Although several studies has been demonstrating how CSO can be treated using constructed wetlands [22, 23], these techniques need a large availability of land to be properly implemented, and consequently they can hardly find application in a dense inhabited urban area, such as Shenzhen is one. 
Consequently, it appears clear that the most sustainable intervention to mitigate $\mathrm{CSO}$ in a relative short period is to intercept as many as possible sanitary sewers temporary preventing their flow into the combined sewers in case of heavy rain. Sanitary sewage discharge volume in Dasha River is $90000 \mathrm{~m}^{3} /$ day. In a scenario of $50 \%$ catchments diversion into underground tanks, the total volume which needs to be stored every hour is $1875 \mathrm{~m}^{3}$. Considering to use prefab tanks that can be easily transported (the size of a $6 \mathrm{~m}$ long container), $50 \%$ of sanitary sewage can be stored in about 125 of these tanks installed underground, which will be filled in a period of time of 2 hours. 250 tanks can totally free the sewers from sanitary sewage for the same period of time ( 2 hours), during rain picks. The tanks must be provided with an integrated valve technology, able to stop the flux when needed. The system should work as following: sanitary sewage should pass through the tank in normal conditions. The entrance hole have to be placed in the upper part of the tank, the exit hole in the bottom part an provided with a valve. In normal working condition the valve it is open an the tank empty. In case of heavy rain the valve closes. The tank must be also provided with a relief system, which will start discharging when the tank is full.

This first intervention should be combined with a gradual introduction of green infrastructure, in order to combine gray and green strategies, as it is proved to be the most effective scheme [24].

\section{Conclusions}

- During heavy rainfall events, the combined sewage system constructed under the banks of Dasha River is overflowing, producing uncontrolled depletion of the water quality first in the river and later in Shenzhen Bay where the river is discharging.

- $\mathrm{CSO}$ is due to several reasons, among which the most relevants are: the magnitude of the wet precipitation, the tremendous growth of impervious surfaces and the structural limits of the system.

- In a long term perspective, the construction of a Sponge City is the most sustainable strategy, which imply the construction of green infrastructures for water storage and filtration.

- On a medium time horizon separating stormwater discharge from sanitary sewage it is probably the most feasible strategy. 125 tanks can provide room to store $50 \%$ of sanitary sewage discharge during two pick hours of heavy rainfall event.

- Future studies are needed to set up guidelines for the construction of the Sponge-City and to precisely define implementation schemes for separating sanitary sewers. 


\section{References}

[1] World Bank. East Asia's Changing Urban Landscape: Measuring a Decade of Spatial Growth, Urban Development Series, World Bank: Washington, DC, p. 12, 2015

[2] Huang X., Schneider A., Friedl M.A., Mapping sub-pixel urban expansion in China using MODIS and DMSP/OLS nighttime lights, Remote Sensing of Environment 175, Elsevier: Amsterdam, pp. 92-108, 2016

[3] Hu, Y. \& Jia G., Influence of land use change on urban heat island derived from multi-sensor data, International Journal of Climatology, Volume 30, Issue 9, pp. 1382-1395, 2010

[4] Alberti, M., Booth D., Hill K., Coburn B., Avolio C., Coe S., Spirandelli D., The impact of urban patterns on aquatic ecosystems: an empirical analysis in Puget lowland sub-basins, Landscape and Urban Planning, Volume 80, pp. 345-361, 2007

[5] Arnold, C.L., Gibbons, C.J., Impervious surface coverage: emergence of a key environmental indicator, Journal of the American Planning Association, Volume 62, No. 2, pp. 243-258, 1996

[6] Burges, S. J., Wigmosta, M. S., and Meena, J. M., Hydrological Effects of Land-Use Change in a Zero-Order Catchment, Journal of Hydrologic Engineering, Volume 3, Issue 2, pp. 86-97, 1998

[7] Blair, R.B., Land use and avian species diversity along an urban gradient, Ecological Applications, Volume 6, No. 2, pp. 506-519, 1996

[8] Trombulak, S.C., Frissell, C.A., Review of ecological effects of roads on terrestrial and aquatic communities, Conservation Biology, Volume 14, No. 1, 18-30, 2000

[9] Liu Z., Wang Y., Li Z. and Peng J., Impervious surface impact on water quality in the process of rapid urbanization in Shenzhen, China, Environmental Earth Sciences, Volume 68, Issue 8, pp. 2365-2373, 2013

[10] Mejía, A. and Moglen, G., Impact of the spatial distribution of imperviousness on the hydrologic response of an urbanizing basin, Hydrological Processes, Volume 24, Issue 23, pp. 3359-3373, 2010

[11] Boyd, M. J., Bufill, M. C., \& Knee, R. M., Pervious and impervious runoff in urban catchments, Hydrological Sciences Journal, Volume 38, Issue 6, pp. 463-478, 1993

[12] Fu, P. \& Weng Q., A time series analysis of urbanization induced land use and land cover change and its impact on land surface temperature with Landsat imagery, Remote Sensing of Environment, Volume 175, pp. 205214, 2016

[13] Madoux-Humery A.S., Dorner S., Sauv e S., Aboulfadl K., Galarneau M., Servais P., Pr evost M., The effects of combined sewer overflow events on riverine sources of drinking water, Water Research, Volume 92, pp. 218227,2016 
[14] Jalliffier-Verne I., Heniche M., Madoux-Humery A.S., Galarneau M., Servais P., Prevost M., Dorner S., Cumulative effects offecal contamination from combined sewer overflows: Management for source water protection, Journal of Environmental Management, Volume 174, pp. 62-70, 2016

[15] Jalliffier-Verne, I., Leconte, R., Huaringa Alvarez, U.F., Madoux-Humery, A.S., Galarneau, M., Servais, P., Prevost, M., Dorner, S., Impacts of global change on the concentrations and dilution of combined sewer overflows in a drinking water source, Science of The Total Environment, Volume 508, pp. 462-476, 2014

[16] Shenzhen Water Planning and Design Institute, Dasha river transformation project design specification, 2009

[17] Wang M.Y., Personal communication, 16 June 2015, Designer at Shenzhen Water Planning and Design Institute, Shenzhen, PRC.

[18] Water Resources Bureau of Shenzhen Municipality, W.R.B., Shenzhen flood control and river regulation plan (2014 - 2020), 2014

[19] Alyaseri I. \& Zhou J.P., Stormwater Volume Reduction in Combined Sewer Using Permeable Pavement: City of St. Louis, Journal of Environmental Engineering, Volume 142, Issue 4, 2016

[20] Pratt C. J., Mantle J. D. G., Schofield P. A., Urban Stormwater Reduction and Quality Improvement through the Use of Permeable Pavements, Volume 21, Issues 8-9, pp. 769-778, 1989

[21] Legret, M., Colandini V. \& Le Marc C., Effects of a porous pavement with reservoir structure on the quality of runoff water and soil, Science of The Total Environment, Volumes 189-190, pp. 335-340, 1996

[22] Meyer D. \& Ulrich Dittmer, U., RSF_Sim - A simulation tool to support the design of constructed wetlands for combined sewer overflow treatment, Ecological Engineering, Volume 80, pp. 198-204, 2015

[23] Pálfy, T.G., Molle, P., Langergraber G., Troesch S., Gourdon R. \& Meyer, D., Simulation of constructed wetlands treating combined sewer overflow using HYDRUS/CW2D, Ecological Engineering, Volume 87, pp. 340-347, 2016

[24] Tavakol-Davani, H.; Burian, S.J., Devkota, J. \& Apul D., Performance and Cost-Based Comparison of Green and Gray Infrastructure to Control Combined Sewer Overflows, Journal of Sustainable Water Built Environment, Volume 2, Issue 2, 2016 